\title{
Residency training in family medicine and its impact on coordination and continuity of care: an analysis of referrals to secondary care in Rio de Janeiro
}

\section{Adelson Guaraci Jantsch}

Universidade do Estado do Rio de Janeiro https://orcid.org/0000-0002-3012-5619

\section{Bo Burström}

Department of Global Public Health at the Karolinska Institute

\section{Gunnar Nilsson}

Department of Neurobiology, Care Sciences and Society at the Karolinska Institute https://orcid.org/0000-00017811-7602

Antônio Ponce de Leon ( $\square$ antonio.ponce.de.leon.2@ki.se )

Department of Global Public Health at the Karolinska Institute https://orcid.org/0000-0002-0704-5215

\section{Research Article}

Keywords: Primary Health Care, Family Practice, Health Workforce, Developing Countries

Posted Date: March 22nd, 2021

DOI: https://doi.org/10.21203/rs.3.rs-350593/v1

License: (c) (1) This work is licensed under a Creative Commons Attribution 4.0 International License. Read Full License

Version of Record: A version of this preprint was published at BMJ Open on February 1st, 2022. See the published version at https://doi.org/10.1136/bmjopen-2021-051515. 


\section{Abstract}

Objective: To measure the effect that Residency Training in Family Medicine (RTFM) has on continuity and coordination of care.

Design: Observational cohort study using electronic health records.

Setting: Rio de Janeiro, Brazil, public primary care system.

Participants: 504940 patients, 633 generalists (physicians without RTFM) and 204 Family physicians (FP - doctors with two years of RTFM) from one health district between January 2015 and December 2018.

Intervention: Two years of Residency Training in Family Medicine (RTFM)

Main outcome measures: risk of patients being referred to secondary care for outpatient consultations and diagnostics tests; and having a follow-up medical consultation in primary care within three and six months after being referred.

Results: We examined 2414508 medical consultations and 284754 referrals to secondary care. Family physicians (FPs) were less likely to request ambulatory care services (including surgical specialties), but were more likely to request Ophthalmology, Physiotherapy, Rehabilitation, and Surgical evaluations for their patients. Patients referred to secondary care by FPs were at a higher risk of having a follow-up visit in primary care for almost every service requested. If all medical consultations were performed by FPs, a 37.6\% (95\% Cl 32.4\% - 42.4\%) increased demand for Rehabilitation services would be noticed. Oppositely, 1532 (95\% Cl 1458; 1602) fewer requests for Dermatology would happen every year.

Conclusions: RTFM improves coordination and continuity of care by making FPs more competent to retain those health conditions that can be properly managed in primary care and making FPs more competent to detect health conditions that require specific biomedical technologies and skills, increasing the demand for those services. Besides, it increases the chances of patients having follow-up visits in primary care. Policymakers in low-and middle-income countries must consider investing in RTFM to make primary care systems more comprehensive, with better coordination and continuity of care.

\section{Article Summary}

Strengths and limitations of this study

- To our knowledge, our article is the first study to address the impact of residency training in Family Medicine on promoting continuity and coordination between primary and secondary levels of healthcare in low- and middleincome countries.

- We drew on data from electronic health records, which reflect real-world clinical practice in the public primary care system in Brazil, and using mixed-effects models allowed us to take into account the correlation among consultations from the same patient.

- Our analyses are limited to comparisons on patterns of referrals and follow-ups between Generalists and Family physicians and we cannot infer that patients are getting a better quality of care, having better quality of life or living longer.

- Having the full information about doctors' individual and educational characteristics would have helped to better measure the role that residency training in Family Medicine plays in promoting the attributes of PHC. 
- The evidence raised from primary care and Family Medicine in Brazil can be better translated to other low- and middle-income countries that are facing similar troubles training the healthcare workforce and developing comprehensive primary health care systems.

\section{Introduction}

For the last 40 years, improvements in Primary Health Care (PHC) were made worldwide due to the momentum created by the Alma-Ata declaration. ${ }^{1}$ Many countries have achieved good results in creating and developing universal, accessible, and cost-effective PHC systems. ${ }^{2,3}$ Today we have enough evidence supporting the notion that countries with strong $\mathrm{PHC}$ have better health indicators, ${ }^{4}$ have reduced health inequalities, ${ }^{5}$ and get better results while spending less money. ${ }^{6}$

With a large universal public health care system ${ }^{7}$ and a successful history of community-based $\mathrm{PHC}^{8}$ Brazil has been $^{\circ}$ portrayed as an example to be followed by low- and middle-income countries (LMIC). The Family Health Strategy (Estratégia de Saúde da Família - FHS) launched by the federal government in 1994, established a structure for PHC at the municipal level, providing financial resources for Family Health Teams (FHT) formed by one physician, one nurse, one nurse assistant and four to six Community Health Workers (CHW) to provide care for up to 4000 people living in a given catchment area. This initiative has substantially reduced infant and neonatal mortality, ${ }^{9}$ hospital admissions related to ambulatory-care sensitive conditions, ${ }^{10-13}$ and cardiovascular deaths. ${ }^{14,15}$ Today 43,000 FHTs provide public-funded community-based $\mathrm{PHC}$ to $64 \%$ of the Brazilian population covered by the FHS. ${ }^{16}$ However, many of these FHTs have only a nurse and $\mathrm{CHW}$ as health care providers and, when a doctor is available, it is very unlikely to be a trained Family Physician (FP).

Despite recent policies that have tried to boost the creation and growth of residency programs in Family Medicine (FM) in Brazil, ${ }^{17,18}$ only $4.4 \%$ of the residency seats are dedicated to FM. With only $5,500 \mathrm{FP}$ in the country ${ }^{19}(1.4 \%$ of all medical specialists), FM is still not seen by policymakers and health managers as a necessary medical specialty for doctors working in $\mathrm{PHC}^{20}$

Between 2008 and 2016, the Rio de Janeiro Municipal Health Department (RJ-MHD) expanded the FHS coverage from 3.5 to $70 \%$ in the city and allocated financial incentives for capacity building of human resources in FM. ${ }^{21} \mathrm{~A}$ new FM residency training program was created and two established programs were expanded. ${ }^{22,23}$ The rationale behind this initiative was that the investments made in residency training in FM (RTFM) would be translated into a more qualified provision of $\mathrm{PHC}$ with a wider scope of practice and better use of health resources. ${ }^{24}$

Measuring the impact that RTFM can make in promoting the attributes of PHC can be a hard task due to its characteristics, complexity and broad scope of practice, making it necessary to approach one aspect at a time. With FPs and Generalists (physicians without RTFM) working side by side for the last 10 years, the city of Rio de Janeiro can be a unique case study to address important research questions about the development of human resources for $\mathrm{PHC}$ in LMIC. ${ }^{25}$

This study analyzes the impact of RTFM on two key attributes of PHC - continuity and coordination of care - by testing the hypothesis that trained FPs will be less likely to refer their patients to secondary care, but will be more likely to provide follow-up visits for patients once referred. It aims to compare FPs and Generalists performance by measuring (1) the risk of their patients being referred to SC for outpatient consultations and diagnostic tests; (2) the risk of those patients having a follow-up medical consultation in PHC within three and six months after being referred. 
Finally, it aims (3) to determine the population attributable fractions (PAFs) in a scenario in which all medical consultations and referrals were carried out by FPs.

\section{Methods}

\section{STUDY DESIGN AND DATA SOURCE}

We conducted a retrospective longitudinal observational analysis of medical consultations in PHC and referrals to SC. This sample combines information from 504.940 patients (205.961 men and 298.508 women), 2.414.508 medical consultations, 284.754 referrals to SC, and 837 physicians working non-concurrently in one health district between January 2015 and December 2018. Patients' consent was not necessary since only anonymized information was used during the study and the RJ-MHD, the actual caretaker of this information, gave the consent to use this dataset for this research. The study was approved by the RJ-MHD research ethics board and it is registered under the number 03795118.0.0000.5279. It was conducted in accordance with the 466/12 resolution from the Brazilian National Health Council $^{26}$ and the Declaration of Helsinki.

\section{EXPOSURE}

Physicians were divided into two categories: (1) Generalists - the reference category aggregating doctors without residency training in FM; and (2) Family physicians (FP) - graduated family physicians, FM preceptors and residents enrolled in the FM residency programs. Residents in FM were included in the same category as FP because they spend two years working 48 hours a week in a community-based primary care clinic under the full supervision of a senior FP (FM preceptor), sharing responsibilities for the same patients in one FHT. Every week they have learning sessions developed by the faculty members ${ }^{23}$ using active learning methods ${ }^{27,28}$ to address topics of FM and PHC, such as clinical reasoning, management of the most prevalent health conditions in $\mathrm{PHC}$, communication skills, evidence basedmedicine, PHC and health care systems, vulnerable populations, elderly care, multimorbidity, polypharmacy, among others. ${ }^{29}$ They also have rotations in maternal care, pediatrics, internal medicine, and emergency care. These activities were designed in line with the National Committee for Medical Residencies (CNRM) ${ }^{30}$ and with the Brazilian Society of Family and Community Medicine (SBMFC). ${ }^{31}$ Information about other forms of post-graduate training were not available in the database and were not taken into account, nor the number of years in practice for any doctor.

\section{INDEPENDENT VARIABLES}

Every patient contributed to the models with individual information - (1) age (linear), (2) sex, and (3) the Charlson Comorbidity Index ${ }^{32}$ - and contextual information - (4) the Social Development Index (SDI). The SDI is a linear scale combining information about sanitation, schooling, income, and housing conditions from every household in the FHT catchment area, representing the grade of social development of a neighborhood. ${ }^{33}$ Hence, patients registered in the same FHT have the same SDI. It varies from 0 (least developed) to 1 (most developed).

Charlson Comorbidity Index ${ }^{32}$ was used to add information about patients' morbidity burden to the models, assuming that those with more chronic conditions would be more likely to be referred to secondary care and have follow-up consultations after being referred.

Time effects were regarded using dummy variables for months and years in all models. A dummy variable was used to include information identifying if the consultation was a prenatal care visit or not. 
All clinics in this sample have the same physical structure, offices equipped with computer, printer, medical equipment, room for small surgical procedures, the same arsenal of laboratory tests and medicines in the pharmacy, and the same type of human resources available: nurses, technicians, dentists, pharmacists, and managers. The availability of medical specialties in SC and diagnostics tests, and the referral procedures are the same for all doctors and clinics in the sample. The distribution of doctors among different clinics and FHT didn't follow any criteria that could interfere in the relationship between the medical categories, the population assisted, and the study outcomes.

\section{OUTCOMES}

Referrals to SC were divided into three groups: (1) outpatient consultations for ambulatory care; (2) surgical evaluation; and (3) diagnostics tests. They were considered as a binary event (referred versus non-referred). To estimate the relative risks (RR) of having a follow-up visit in the PHC clinic after the referral, only patients who had been referred to the specific specialty under analysis were considered. Follow up visits were also considered binary events categorized as the patient having or not having one medical consultation (a) 90 days after the referral or (b) 180 days after the referral. The 32 most commonly requested medical specialties consultations and diagnostics tests in our dataset were used to perform this analysis.

Comparing both the risk of a patient being referred to SC and the risk of having a follow-up visit by doctors with different types of training can bring us evidence about the effect that RTFM has on promoting both a more effective healthcare for the patient in primary care and a better continuity of care and coordination between primary and secondary levels of care. This notion is aligned with the definition of FM from the Brazilian, ${ }^{31}$ Canadian $^{34}$ and European ${ }^{35}$ curricula for FM, i.e., that experts in FM "are skilled clinicians that are capable of managing a full range of health conditions", "make efficient use of health care resources through coordinating care" and "are responsible for the provision of longitudinal continuity of care as determined by the needs of the patient."

\section{STATISTICAL ANALYSES}

Multilevel multivariate binomial regression models were used to estimate the RRs of patients being referred to SC in one medical consultation and patients having a follow-up visit in three and six months after being referred to SC, according to the medical category of the doctor in charge. A hierarchical data structure was created with consultations from the same patient clustered and ordered per each individual patient, taking into account the correlation among consultations from the same patient.

Each outcome was analyzed individually. Mammography, Gynecology and Gynecologic Surgery entailed just women and high-risk prenatal care (HRPC) entailed only pregnant women. Models were adjusted for first level covariates (consultation), i.e., patient's age, patient's Charlson Comorbidity Index, prenatal care consultation, time, and medical category; and for second level covariates - SDI and patient's sex.

Variance partition coefficients were calculated for all adjusted models in order to explore the proportion of the variance attributed to the second level, i.e., the variance attributed to patients characteristics. ${ }^{36}$

PAF for each requested service was calculated using the RR from the multivariate regression models to estimate the impact in the number of referrals requested per year in the same health care district if all medical consultations were performed by trained FPs. ${ }^{37,38}$ Data processing and statistical analysis were performed using R version 3.6.2 and Ime4 package.

\section{Results}


A similar proportion of women (2/3) and men (1/3) with a small difference for age and SDI distributions was seen by FPs and generalists. Each subgroup had patients from the most affluent (SDI $=0.689)$ and the least affluent areas (SDI $=0.416$ ). Although doctors in the sample had not necessarily worked throughout the entire study period, the proportion in the sample represents the distribution of the categories among 30 clinics and 196 FHT (Table 1).

Ambulatory care services were less likely to be requested by FPs, except for Ophthalmology, Physiotherapy, and Rehabilitation, which were requested more frequently by FPs (Table 2). Surgical specialties tended to be requested less often by FPs to ambulatory care in ENT, Orthopedics, General Surgery, Gynecology, Vascular Surgery, and Urology. When the referral was related to surgical evaluation in Plastic Surgery, Orthopedic Surgery or Eye Surgery, FPs tended to refer their patients more frequently.

Diagnostic tests, such as Colonoscopy, Echocardiogram, EGD, and CPX tests were less frequently requested by FPs. Spirometry and Mammography were the only exceptions.

Patients referred to SC by FPs were at a higher risk of having a follow-up visit in primary care after three and six months than those referred by Generalists for almost every service requested. HRPC was the only ambulatory care service that FPs and Generalists presented similar risk of a patient having a follow-up visit in the three and six-months period (Table 3).

In a hypothetical scenario where all medical consultations were performed by FPs, all medical specialties would experience a decrease in demand for ambulatory care, with Angiology being, in relative terms, the most affected - PAF $55.6 \%(95 \% \mathrm{Cl} 51.3 \% ; 58.9 \%)$ - and Dermatology and Orthopedics having the biggest absolute reduction, with 1532 $(95 \% \mathrm{Cl} 1458 ; 1602)$ and $1696(95 \% \mathrm{Cl} 1612 ; 1780)$ fewer requests every year. Contrarily, replacing Generalists by FPs would increase by $37.6 \%$ (95\% Cl 32.4\%; 42.4\%) the demand for Rehabilitation services and by $13.3 \%$ (95\% $\mathrm{Cl} 10.9 \%$; $16.2 \%$ ) the demand for Eye Surgery (Table 2). Surgical specialties such as Plastic Surgery and Orthopedic Surgery would have an increase in demand for consultations, while ENT and General Surgery would have a decrease in demand. For these two surgical specialties there would be $439(95 \% \mathrm{Cl} 374 ; 506)$ and $111(95 \% \mathrm{Cl} 48 ; 174)$ fewer requests every year, respectively.

At the same time, the demand for most of the diagnostics tests would decrease, and $403(95 \% \mathrm{Cl} 365 ; 441)$ fewer EGD tests and $277(95 \% \mathrm{Cl} 232 ; 315)$ fewer Echocardiograms would be requested every year.

Although the inclusion of the age, sex, SDI, time, and the $\mathrm{CCl}$ in the models slightly changed the effect sizes and confidence intervals of the main exposure, these variables were kept in the models that provided the RRs and PAFs reported here. Variance-inflation factors were always below 3 in all models.

The partition coefficients of variance (VPC) showed that the proportion of variance attributed to the second level (patient characteristics) is more important for the occurrence of a referral than for the occurrence of a follow-up visit, with a consistent pattern for all types of services studied. The proportion of the variance attributed to the patient level for Pulmonology, Endocrinology and Spirometry, for example, are up to $53 \%, 40 \%$ and $43 \%$. At the same time, for the risks of follow-up visits for those patients referred to these three services, no more than $0.05 \%, 0.03 \%$ and $0.01 \%$ of the variance can be attributed to differences between patients.

\section{Discussion}

This research has taken a non-judgmental approach to the doctor-patient clinical encounter. It considers that every doctor in this sample has made the best possible decisions to provide the most appropriate health care to their 
patients and the comparisons between FPs and Generalists aim solely to analyze the patterns behind the numbers that represent the impact of having two extra years of training to work in primary care.

Our study findings highlight a significant distinction in the types of consultation services that are more or less likely to be requested by FPs. When FPs were in charge of the consultation, the number of referrals in half of the ambulatory care specialties decreased by more than $50 \%$. Services that did not require equipment or special skills other than clinical reasoning or general medical skills also had a significantly lower risk. On the other hand, Ophthalmology, Physiotherapy, and Rehabilitation - ambulatory care services that make use of special equipment and demand specific skills to be performed - were more often requested by FPs. (Table 2).

Both Physiotherapy (reserved for minor musculoskeletal injuries) and Rehabilitation (motor, neurological, intellectual, and respiratory rehabilitation, as well as orthosis confection, prosthesis, and stoma care) are services that require specific biomedical technology and skilled professionals to be performed. These are usually available at the secondary level of the health care system. At the same time, Ophthalmology, Plastic surgery (exclusively reconstructive procedures), and Eye surgery followed the same pattern, and patients were more frequently referred by FPs.

Part of the lower risk for requesting a referral to ambulatory care services among FPs can be explained by the learning opportunities that residents have during the two years of training. As part of the learning activities, ${ }^{22}$ residents have case discussions with Dermatologists and Psychiatrists every other week at the clinic. They can book the patients they are facing difficulties to have a joint consultation with a specialist, sharing decisions about diagnostics and management, and discussing the resident's educational needs, based on that case. ${ }^{39}$ Biopsies and small procedures are mostly performed at the clinic as well. Due to its high prevalence, residents are trained in chronic pain management to deal with myofascial pain, to perform dry needling to relief trigger points, and simple physiotherapy exercises that can be performed by the patient alone or with the supervision of the physical educator at the local community gym available in every primary care clinic. Without the supervision of those specialists and the focused training in chronic pain management, FP would probably request referrals to Dermatology, Psychiatry, and Physiotherapy more frequently.

However, the vast majority of the patients, including cases involving skin lesions and mental health issues, are regularly managed by the FHT with the help of a preceptor in FM. Cases that could also have been referred to a General Surgeon, such as lipomas, sebaceous cysts, and skin biopsies, or Vascular Surgery, such as chronic venous insufficiency, are included in the residents' training, making them more competent to manage these conditions in PHC. On the other hand, Plastic surgery (exclusively reconstructive procedures) is another specialty that needs trained professionals to be performed and FPs are more likely to request it.

Learning how to manage the most prevalent health conditions in PHC during RTFM can increase both the awareness about the conditions and the built-in capacity to manage them. The former makes FPs more prepared to recognize and diagnose the condition; the latter provides the necessary tools to treat it. This can explain why FPs are less inclined to request diagnostic tests for their patients. Diagnostic tests are part of the clinical reasoning process and if residents learn how to use them with an evidence-based approach, it is more likely that they will more cautiously select the patients that need them. This is not a new concern in $\mathrm{PHC}^{40}$ and is aligned with the Choosing Wisely ${ }^{41}$ and the Quaternary Prevention ${ }^{42}$ initiatives, that exert a strong influence in the FM community by calling the attention of doctors and patients to the potential harms that unnecessary tests, treatments, and procedures can make. This requires a balanced approach to healthcare that takes into account issues around the underuse and the overuse of tests and/or treatments. Our study shows the distinction between services that patients are less likely from those they are more likely to be referred by FPs. This gives us a clue about what has been requested too much (Cardiology, 
Endocrinology, Allergology) and what has been requested too little (Eye surgery, Orthopedic surgery, Physiotherapy) in the public PHC system in Rio de Janeiro.

In regard to the risk of occurrence of a follow-up visit being consistently higher among FPs, one could argue that the turnover and the shortage of doctors - two common issues in the Brazilian PHC - could have influenced the occurrence of this event. We cannot assure that retention in the same FHT was the same for every category. But if FPs were more inclined to stay working in the same FHT, we would not see a similar risk of follow-up for women referred to HRPC - RR 1.16; 95\% Cl 0.93-1.44 in three months and RR 0.92; 95\% Cl 0.71-1.19 in six months. Pregnant women have regular medical visits in PHC every month in the first semester, every two weeks in the last trimester, and every week in the last month. Of the 3547 women referred to that service ( 885 by FPs and 2662 by generalists), similar proportions had a follow-up visit within three ( $85.6 \%$ by FPS vs. $83.6 \%$ by generalists) and six months ( $89.5 \%$ by FPs vs. $90.2 \%$ by generalists). Comparing to Cardiology, where FPs were more likely to follow-up their patients in three months (RR 1.86; $95 \% \mathrm{Cl} 1.62-2.14$ ) and in six months (RR $1.74 ; 95 \% \mathrm{Cl} 1.48-2.04)$, only $53.9 \%$ and $71.3 \%$ of those referred by Generalists had a follow-up visit in three and six months, while FPs have followed-up $68.3 \%$ and $81.3 \%$ of their referred patients, respectively.

Table 2 highlights in absolute numbers how much change this intervention can make. Some results show a big difference in terms of distribution and provision of specialized care since some of the services would have their demand decreased by more than $50 \%$. The investments made by the RJ-MHD to promote RTFM have already achieved some results, and its impact could be extended to the whole population if a feasible and sustainable expansion plan is put in place. This expansion should account for several variables that were not explored in this study and may rely not only on political will but on individual aspirations and preferences as well.

The variance partition coefficients show us that the proportion of the variance attributed to the patient has major importance in the risk of a referral to SC being requested, but little influence on the occurrence of a follow-up visit. Although patients' information has a major influence on the variance, FPs (a first level variable) reduce significantly the risk of a patient being referred. The little influence that patients' information has on the occurrence of a follow-up visit demands additional studies exploring other aspects affecting it. If aspects related to the physician in charge (FP or generalist) can better explain part of the variance, it would provide another piece of evidence that RTFM improves coordination and, in this case, continuity of care.

Finally, the impact of RTFM cannot be summarized exclusively in terms of referrals to SC. Residents in FM are not trained to perform one task, but to take care of people from cradle to grave. ${ }^{43}$ During two years of RTFM they develop clinical, relational, scholar, and managerial competencies to provide the best patient-centered care in a community. ${ }^{31,44,45}$ They are not trained exclusively to decide if a patient should or should not be referred to SC. This is just a detail of a much larger learning process whose effect goes beyond the RR measured in this study. That being said, it is reasonable to believe that RTFM must have an impact that goes beyond changing patterns of referrals to SC, affecting positively the quality of care delivered, and outcomes related to patients' morbidity and mortality. Without a doubt, further research must be performed testing this hypothesis.

\section{Strengths And Limitations}

Evaluating $\mathrm{PHC}$ is a hard task and we tried to do it by aiming two specific aspects of $\mathrm{PHC}$ - professional training and referrals to SC. The first is a complex intervention and the second a surrogate outcome. Endpoint outcomes, such as hospital-admissions, quality of life, quality of care, patients' satisfaction, survival, and absenteeism in the referral consultations should be studied in the future to draw a clearer dimension of the impact measured in this study. As 
mentioned before, having the full information about doctors' individual and educational characteristics would have helped to better measure the role that training FM plays in the attributes of PHC.

Apart from these limitations, empirical evidence about a real experience from a middle-income country can be better translated to similar countries that face the same difficulties to develop their PHC systems. ${ }^{46}$ This kind of evidence can help to promote the development of FM in countries where PHC is still very incipient, ${ }^{47}$ and FM is often not recognized as a medical specialty. ${ }^{48,49}$

\section{Conclusion}

Training doctors to develop the competencies needed to manage a broad scope of health conditions in PHC is one of the main goals of residency programs in FM. As a public health intervention, RTFM changes the pattern of referrals commonly seen in PHC when only Generalists take care of the population. In summary, it makes FPs more competent to retain those health conditions that can be properly managed in primary care and, at the same time, makes them more capable of detecting health issues that require specific biomedical technologies and skills, increasing the demand for those services. Besides, it increases the chances of a patient having a follow-up visit, improving coordination and continuity of care of their FHT. This is a real change not only in terms of comprehensiveness and coordination of care but also in costs paid by health systems, families, and society. Policymakers should look closely at the findings described in this article and consider carefully that investments in RTFM can make their PHC systems more comprehensive, with better coordination and continuity of care.

\section{Declarations}

\section{ACKNOWLEDGMENTS}

We are very grateful to the colleagues at the Rio de Janeiro Municipal Health Department that gave us support for this research and provided the dataset we used to perform the study. We would also like to thank Dr. Armando Norman for his feedback on the writing and for his suggestions in the discussion section, especially regarding Quaternary Prevention.

\section{PATIENT AND PUBLIC INVOLVMENT}

Patients and/or the public WERE NOT involved in the design, or conduct, or reporting, or dissemination plans of this research.

\section{PATIENT CONSENT FOR PUBLICATION}

Not required.

\section{ETHICS APPROVAL}

The study was approved by the RJ-MHD research ethics board and it is registered under the number 03795118.0.0000.5279. It was conducted in accordance with the 466/12 resolution from the Brazilian National Health Council $^{26}$ and the Declaration of Helsinki.

Provenance and peer review Not commissioned; externally peer reviewed.

Data availability statement No additional data are available as this work draws on de-identified data provided by patients as a part of their routine primary care. 
FUNDING

The authors declare that there is no funding from any source supporting this research.

CONFLICTS OF INTEREST

The authors declare that there is no conflict of interest in publishing this article or in conducting this study.

\section{DATA STATEMENT}

All data used in this research represent patients, health care providers and medical consultations information that are under the protection of the Rio de Janeiro Municipal Health Department. These data can be obtained from the Rio de Janeiro Superintendence of Primary Care (sapsmsrj@gmail.com) under the authorization of the Rio de Janeiro Municipal Health Department Research Ethics Committee (cepsmsrj@yahoo.com.br).

\section{AUTHOR STATEMENT}

This study was designed and conceived by AGJ, BB, GN, APDL. AGJ conducted the first data analysis and wrote the first draft of this manuscript. AGJ and APDL performed the multilevel analysis. AGJ, BB, GN and APDL discussed the results from the multilevel analysis and decided together what were the most relevant information to be reported at the manuscript. BB, GN and APDL reviewed and made comments on the manuscript. AGJ, BB, GN and APDL wrote and have agreed to submit the final version of the manuscript

\section{References}

1. WHO-Unicef. Declaration of Alma-Ata. Int Conf Prim Heal Care. 1978.

2. Watkins DA, Yamey G, Schäferhoff M, et al. The Lancet Commissions Alma-Ata at 40 years: reflections from the Lancet Commission on Investing in Health. Lancet. 2018;392(10156):1434-1460. doi:10.1016/S01406736(18)32389-4

3. Rohde J, Cousens S, Chopra M, et al. 30 years after Alma-Ata: has primary health care worked in countries? Lancet. 2008;372(9642):950-961. https://www.thelancet.com/journals/lancet/article/PIIS0140-6736(08)61405$1 /$ fulltext.

4. Starfield B. Primary Care and Health: A Cross-National Comparison. JAMA J Am Med Assoc. 1991. doi:10.1001/jama.1991.03470160100040

5. Starfield B, Shi L, Macinko J. Contribution of Primary Care to Health Systems and Health. Milbank Q. 2005;83(3):457-502. doi:10.1111/j.1468-0009.2005.00409.x

6. Macinko J, Starfield B, Shi L. The contribution of primary care systems to health outcomes within Organization for Economic Cooperation and Development (OECD) countries, 1970-1998. Heal Serv Res. 2003;38(0017-9124 (Print)):831-865. doi:10.1111/1475-6773.00149

7. Paim J, Travassos C, Almeida C, Bahia L, Macinko J. The Brazilian health system: History, advances, and challenges. Lancet. 2011. doi:10.1016/S0140-6736(11)60054-8

8. Macinko J, Harris MJ. Brazil's Family Health Strategy - Delivering Community-Based Primary Care in a Universal Health System. N Engl J Med. 2015;372(23):2177-2181. doi:10.1056/NEJMp1501140

9. Rasella D, Aquino R, Barreto ML. Reducing Childhood Mortality From Diarrhea and Lower Respiratory Tract Infections in Brazil. Pediatrics. 2010;126(3). doi:10.1542/peds.2009-3197 
10. Pinto LF, Giovanella L. The Family Health Strategy: expanding access and reducing hospitalizations due to ambulatory care sensitive conditions. Cien Saude Colet. 2018;23(6):1903-1914. doi:10.1590/141381232018236.05592018

11. Afonso MPD, Shimizu HE, Merchan-Hamann E, Ramalho WM, Afonso T. Association between hospitalisation for ambulatory care-sensitive conditions and primary health care physician specialisation: A cross-sectional ecological study in Curitiba (Brazil). BMJ Open. 2017. doi:10.1136/bmjopen-2016-015322

12. Dourado I, Oliveira VB, Aquino R, et al. Trends in Primary Health Care-sensitive Conditions in Brazil. Med Care. 2011;49(6):577-584. doi:10.1097/MLR.0b013e31820fc39f

13. Magalhães ALA, Morais Neto OL de. Intra-urban differences in rates of admissions for ambulatory care sensitive conditions in Brazil's Center-West region. Cien Saude Colet. 2017;22(6):2049-2062. doi:10.1590/141381232017226.16632016

14. Rasella D, Harhay MO, Pamponet ML, Aquino R, Barreto ML. Impact of primary health care on mortality from heart and cerebrovascular diseases in Brazil: A nationwide analysis of longitudinal data. BMJ. 2014. doi:10.1136/bmj.g4014

15. Hone T, Rasella D, Barreto M, Atun R, Majeed A. Large Reductions In Amenable Mortality Associated With Brazil's Primary Care Expansion And Strong Health Governance. Health Aff. 2017;36(1):149-158. doi:10.1377/hlthaff.2016.0966

16. Neves RG, Flores TR, Manjourany SSD, Nunes BP, Tomasi E. Time trend of Family Health Strategy coverage in Brazil , its Regions and Federative Units , 2006-2016. Epidemiol Serv Saude. 2016;27(34):1-8. doi:10.5123/S167949742018000300008

17. Storti MMT, de Oliveira FP, Xavier AL. A expansão de vagas de residência de Medicina de Família e Comunidade por municípios e o Programa Mais Médicos. Interface Commun Heal Educ. 2017;21:1301-1313. doi:10.1590/1807-57622016.0511

18. Oliveira FP de, Araújo C de A, Torres OM, Figueiredo AM de, Souza PA, Oliveira FA de. The More Doctors Program and the rearrangement of medical residency education focused on Family and Community Medicine. Interface Comun Saúde, Educ. 2019;23(1):1-16. http://www.scielo.br/pdf/icse/v23s1/1807-5762-icse-23-s1-e180008.pdf.

19. Mário Scheffer. DEMOGRAFIA MÉDICA NO BRASIL 2018. São Paulo; 2018.

20. Anderson MIP, Rodrigues RD. Formação de especialistas em Medicina de Família e Comunidade no Brasil: dilemas e perspectivas. Rev Bras Med Fam e Comunidade. 2011;6(18):19-20.

21. Soranz D, Pinto LF, Penna GO. Themes and Reform of Primary Health Care (RCAPS) in the city of Rio de Janeiro , Brazil article. Cien Saude Colet. 2016:1327-1338. doi:10.1590/1413-81232015215.01022016

22. Justino ALA, Oliver LL, Melo TP de. Implementation of the Residency Program in Family and Community Medicine of the Rio de Janeiro Municipal Health Department , Brazil article. 2016:1471-1480. doi:10.1590/141381232015215.04342016

23. Izecksohn MMV, Teixeira Junior JE, Stelet BP, Jantsch AG. Preceptorship in Family and Community Medicine: challenges and achievements in a Primary Health Care in progress. Cien Saude Colet. 2016:737-746. doi:10.1590/1413-81232017223.332372016

24. Prado Junior JC. Desafios para a expansão de programas de residência em Medicina de Família e Comunidade: a experiência carioca. Rev Bras Med Família e Comunidade. 2015;10(34):1-9.

25. Frenk J, Chen L, Bhutta ZA, et al. Health professionals for a new century: transforming education to strengthen health systems in an interdependent world. Lancet. 2010;376:1923-1958. doi:10.1016/S0140-6736(10)61854-5 
26. Novoa PCR. What changes in Research Ethics in Brazil: Resolution no. 466/12 of the National Health Council. Einstein (São Paulo). 2000;12(1). doi:10.1590/S1679-45082014ED3077

27. Hung W, Jonassen DH, Liu R. Problem-Based Learning. Handb Res Educ Commun Technol. 2008:485-506. doi:10.1016/j.kjms.2010.11.005

28. Wood DF. ABC of learning and teaching in medicine: Problem based learning. Bmj. 2003;326(October 2007):328330. doi:10.1136/bmj.326.7384.328

29. Programa de Residência em Medicina de Família e Comunidade da Secretaria Municipal de Saúde do Rio de Janeiro. Multiplica: Método de Ensino Para Programas de Residência Em Medicina de Família e Comunidade. 1 ed. Rio de Janeiro: SBMFC; 2016. http://portalmultiplica.org/.

30. Ministério da Educação. Comissão Nacional de Residência Médica. http://portal.mec.gov.br/residencias-emsaude/residencia-medica. Published 2020.

31. SBMFC. Currículo Baseado em Competências para Medicina de Família e Comunidade. Currículo Baseado em Competências para Medicina de Família e Comunidade. http://www.sbmfc.org.br/wpcontent/uploads/media/Curriculo Baseado em Competencias(1).pdf. Published 2015. Accessed February 27, 2020.

32. Charlson M, Szatrowski TP, Peterson J, Gold J. Validation of a combined comorbidity index. J Clin Epidemiol. 1994. doi:10.1016/0895-4356(94)90129-5

33. Cavallieri F, Lopes GP. Índice de Desenvolvimento Social - IDS: Comparando as Realidades Microurbanas Da Cidade Do Rio de Janeiro. Rio de Janeiro; 2008.

http://portalgeo.rio.rj.gov.br/estudoscariocas/download/2394_Índice de Desenvolvimento Social_IDS.pdf.

34. Shaws E, Oandasan I, Fowler N. CanMEDS-FM 2017: A competency framework for family physicians across the continuum. The College of Family Physicians of Canada - Le Collège des Médecins de Famille du Canada. https://www.cfpc.ca/uploadedFiles/Resources/Resource_Items/Health_Professionals/CanMEDS-FamilyMedicine-2017-ENG.pdf. Published 2017. Accessed February 27, 2020.

35. EURACT Council. THE EUROPEAN DEFINITION OF GENERAL PRACTICE/FAMILY MEDICINE. https://www.woncaeurope.org/sites/default/files/documents/Definition EURACTshort version revised 2011.pdf. Published 2011. Accessed January 1, 2020.

36. Goldstein H, Browne W, Rasbash J. Partitioning variation in multilevel models. Underst Stat. 1(4):223-231. doi:https://doi.org/10.1207/S15328031US0104_02

37. Mansournia MA, Altman DG. Population attributable fraction. BMJ. 2018;757(February):2-3. doi:10.1136/bmj.k757

38. World Health Organization. Population Attributable Fraction (PAF). Health statistics and information systems. https://www.who.int/healthinfo/global_burden_disease/metrics_paf/en/. Published 2020. Accessed April 25, 2020.

39. Eve R. PUNs and DENs: Discovering Learning Needs in General Practice. 1st editio. CRC Press; 2001.

40. Wilkin D, Smith AG. Variation in general practitioners' referral rates to consultants. J R Coll Gen Prctitioners. 1987; (August):0-3.

41. Levinson W, Kallewaard M, Bhatia RS, Wolfson D, Shortt S, Kerr EA. 'Choosing Wisely': a growing international campaign. BMJ. 2014;(December):1-9. doi:10.1136/bmjqs-2014-003821

42. Jamoulle M. Quaternary prevention, an answer of family doctors to overmedicalization. Int J Heal Policy Manag. 2015;4(2):61-64. doi:10.15171/ijhpm.2015.24

43. Freeman TR. McWhinney's Textbook of Family Medicine.; 2016. doi:10.1093/med/9780199370689.001.0001

Page $12 / 17$ 
44. EURACT. The EURACT Educational Agenda Of General Pratctice/Family Medicine.; 2005.

45. Stewart M, Brown JB, Weston W, McWhinney IR, McWilliam CL, Freeman T. Patient-Centered Medicine: Transforming the Clinical Method. 3rd Ed. Radcliffe Medical Press; 2014.

46. Dye C, Boerma T, Evans D, et al. The World Health Report 2013: Research for Universal Health Coverage.; 2014.

47. Arya N, Gibson C, Ponka D, et al. Family medicine around the world: overview by region. Can Fam Physician. 2017;63(June 2017):436-441.

48. Ponka D. The Besrour Papers: Seeking evidence for family medicine. Afr J Prim Heal Care Fam Med. 2017:1-2. doi:10.4102/phcfm.v9i1.1559

49. Ponka D, Rouleau K, Arya N, et al. Developing the evidentiary basis for family medicine in the global context. Can Fam physician Médecin Fam Can. 2015;61(7):596-600.

\section{Tables}

Table 1: Number of medical consultations and patients' characteristics according to each medical category in the study sample. Rio de Janeiro, Brazil, 2015 - 2018.

\begin{tabular}{|c|c|c|c|c|c|c|c|c|c|}
\hline \multirow[t]{2}{*}{$\begin{array}{l}\text { Medical } \\
\text { category }\end{array}$} & \multirow{2}{*}{$\begin{array}{l}\text { Number } \\
\text { of } \\
\text { doctors } \\
-\mathrm{N}(\%)\end{array}$} & \multirow[t]{2}{*}{$\begin{array}{l}\text { Consultations } \\
-N(\%)\end{array}$} & \multirow{2}{*}{$\begin{array}{l}\text { Referrals per } \\
100 \\
\text { consultations }\end{array}$} & \multirow{2}{*}{$\begin{array}{l}\text { SDI - } \\
\text { mean } \\
(S D)\end{array}$} & \multicolumn{3}{|c|}{ Patients age (\%) } & \multicolumn{2}{|c|}{$\begin{array}{l}\text { Patients according to } \\
\text { sex }-\mathrm{N}(\%)\end{array}$} \\
\hline & & & & & $<18$ & $\begin{array}{l}>18 \\
\&< \\
45\end{array}$ & $>45$ & Women & men \\
\hline Generalists & $\begin{array}{l}633 \\
(75.6)\end{array}$ & $\begin{array}{l}1.629 .235 \\
(67.5)\end{array}$ & 12.7 & $\begin{array}{l}0.573 \\
(0.03)\end{array}$ & 21.3 & 31.8 & 46.9 & $\begin{array}{l}1.067 .212 \\
(65.6)\end{array}$ & $\begin{array}{l}562.023 \\
(34.4)\end{array}$ \\
\hline $\begin{array}{l}\text { Family } \\
\text { physicians }\end{array}$ & $\begin{array}{l}204 \\
(24.4)\end{array}$ & $\begin{array}{l}785.273 \\
(32.5)\end{array}$ & 9.9 & $\begin{array}{l}0.585 \\
(0.03)\end{array}$ & 18.5 & 34.5 & 47.0 & $\begin{array}{l}517.813 \\
(65.9)\end{array}$ & $\begin{array}{l}267.460 \\
(34.1)\end{array}$ \\
\hline
\end{tabular}


Table 2: Relative risk of a patient being referred to SC in one medical consultation in PHC according to the medical category of the doctor in charge - Generalists (reference) and Family physicians. Rio de Janeiro, Brazil, 2015 2018.

\begin{tabular}{|c|c|c|c|c|}
\hline $\begin{array}{l}\text { Medical } \\
\text { Specialty }\end{array}$ & $\begin{array}{l}\text { Family } \\
\text { physicians }\end{array}$ & $\begin{array}{l}\text { Average } \\
\text { number of } \\
\text { referrals per } \\
\text { year }\end{array}$ & $\begin{array}{l}\text { Population } \\
\text { attributable } \\
\text { fraction \% (95\% } \\
\text { Cl) }\end{array}$ & $\begin{array}{l}\text { Change (and } 95 \% \mathrm{CI} \text { ) in the number of } \\
\text { referrals per year if all doctors were } \\
\text { family physicians }\end{array}$ \\
\hline \multicolumn{5}{|c|}{ Ambulatory care } \\
\hline Cardiology & $\begin{array}{l}0.4(0.38- \\
0.43)\end{array}$ & 2008 & $\begin{array}{l}-50.3(-47.2 \\
-52.4)\end{array}$ & $-1010(-948 ;-1052)$ \\
\hline Neurology & $\begin{array}{l}0.5(0.47- \\
0.53)\end{array}$ & 1835 & $\begin{array}{l}-40.3(-37.4 \\
-43.2)\end{array}$ & $-740(-686 ;-793)$ \\
\hline Psychiatry & $\begin{array}{l}0.45(0.4- \\
0.5)\end{array}$ & 897 & $\begin{array}{l}-45.2(-40.3 \\
-50.3)\end{array}$ & $-405(-361 ;-451)$ \\
\hline Dermatology & $\begin{array}{l}0.49(0.47- \\
0.51)\end{array}$ & 4144 & $\begin{array}{l}-41.3(-39.3 \\
-43.2)\end{array}$ & $-1711(-1629 ;-1790)$ \\
\hline Pulmonology & $\begin{array}{l}0.54(0.48- \\
0.6)\end{array}$ & 903 & $-36.5(-31 ;-42.2)$ & $-330(-280 ;-381)$ \\
\hline $\begin{array}{l}\text { Infectious } \\
\text { Diseases }\end{array}$ & $\begin{array}{l}0.74(0.63- \\
0.87)\end{array}$ & 290 & $-19.2(-9.2 ;-28.4)$ & $-56(-27 ;-82)$ \\
\hline Urology & $\begin{array}{l}0.57(0.54- \\
0.61)\end{array}$ & 1762 & $\begin{array}{l}-33.7(-30.1 \\
-36.5)\end{array}$ & $-594(-530 ;-643)$ \\
\hline Allergology & $\begin{array}{l}0.54(0.47- \\
0.6)\end{array}$ & 480 & $-36.5(-31 ;-43.2)$ & $-175(-149 ;-207)$ \\
\hline Nephrology & $\begin{array}{l}0.63(0.57- \\
0.7)\end{array}$ & 603 & $\begin{array}{l}-28.4(-22.4 \\
-33.7)\end{array}$ & $-171(-135 ;-203)$ \\
\hline Endocrinology & $\begin{array}{l}0.42(0.38- \\
0.46)\end{array}$ & 1021 & $\begin{array}{l}-48.2(-44.2 \\
-52.4)\end{array}$ & $-492(-451 ;-535)$ \\
\hline Gastroenterology & $\begin{array}{l}0.38(0.34- \\
0.42)\end{array}$ & 867 & $\begin{array}{l}-52.4(-48.2 \\
-56.7)\end{array}$ & $-454(-418 ;-492)$ \\
\hline Angiology & $\begin{array}{l}0.35(0.32- \\
0.39)\end{array}$ & 1030 & $\begin{array}{l}-55.6(-51.3 \\
-58.9)\end{array}$ & $-573(-528 ;-607)$ \\
\hline Rheumatology & $\begin{array}{l}0.47(0.42- \\
0.52)\end{array}$ & 830 & $\begin{array}{l}-43.2(-38.4 \\
-48.2)\end{array}$ & $-359(-319 ;-400)$ \\
\hline Physiotherapy & $\begin{array}{l}1.17(1.11- \\
1.23)\end{array}$ & 2390 & $10.9(7.2 ; 14.4)$ & $261(172 ; 344)$ \\
\hline Rehabilitation & $\begin{array}{l}1.68(1.57- \\
1.79)\end{array}$ & 1173 & $37.6(32.4 ; 42.4)$ & $441(380 ; 497)$ \\
\hline Ophthalmology & $\begin{array}{l}1.09 \text { (1.06- } \\
1.12)\end{array}$ & 8713 & $5.9(4 ; 7.8)$ & $514(349 ; 680)$ \\
\hline ENT & $\begin{array}{l}0.71(0.67- \\
0.75)\end{array}$ & 2269 & $\begin{array}{l}-21.6(-18.4 \\
-24.9)\end{array}$ & $-490(-417 ;-565)$ \\
\hline Orthopedics & $\begin{array}{l}0.52(0.5- \\
0.54)\end{array}$ & 4934 & $\begin{array}{l}-38.4(-36.5 \\
-40.3)\end{array}$ & $-1895(-1801 ;-1988)$ \\
\hline Gynecology & 0.86 (0.79- & 738 & $-9.9(-4.1 ;-15.2)$ & $-73(-30 ;-112)$ \\
\hline & & & Page $14 / 17$ & \\
\hline
\end{tabular}


HRPC $\quad 0.66(0.6-991 \quad-25.8(-20.8 ;-31) \quad-256(-206 ;-307)$

Surgical evaluation

\begin{tabular}{|c|c|c|c|c|}
\hline Eye Surgery & $\begin{array}{l}1.21(1.17- \\
1.26)\end{array}$ & 4458 & $13.3(10.9 ; 16.2)$ & $593(486 ; 722)$ \\
\hline $\begin{array}{l}\text { Gynecologic } \\
\text { Surgery }\end{array}$ & $\begin{array}{l}0.87(0.81- \\
0.95)\end{array}$ & 989 & $-9.2(-3.4 ;-13.7)$ & $-91(-34 ;-135)$ \\
\hline $\begin{array}{l}\text { Orthopedic } \\
\text { Surgery }\end{array}$ & $\begin{array}{l}1.22(1.02- \\
1.47)\end{array}$ & 147 & $13.9(1.3 ; 27.5)$ & $20(2 ; 40)$ \\
\hline General Surgery & $\begin{array}{l}0.91(0.86- \\
0.96)\end{array}$ & 1968 & $-6.3(-2.7 ;-9.9)$ & $-124(-53 ;-195)$ \\
\hline Plastic Surgery & $\begin{array}{l}1.19(1.1- \\
1.29)\end{array}$ & 859 & $12.1(6.5 ; 17.9)$ & $104(56 ; 154)$ \\
\hline Vascular Surgery & $\begin{array}{l}0.87 \text { (0.77- } \\
0.99)\end{array}$ & 359 & $-9.2(-0.7 ;-16.8)$ & $-33(-3 ;-60)$ \\
\hline
\end{tabular}

Diagnostic tests

Echocardiogram $0.66(0.62-\quad 1201$

0.71)

$\begin{array}{ll}\text { Spirometry } & 0.96(0.85-\quad 38 \\ 1.09)\end{array}$

$\begin{array}{llll}\text { Colonoscopy } & 0.76(0.68- & 510 & -17.6(-10.6 ; \\ & 0.85) & -24.1) & -90(-54 ;-123)\end{array}$

$\begin{array}{llll}\text { EGD } & 0.49(0.45- & 1090 & -41.3(-37.4 ; \\ 0.53) & & -45.2) & -450(-408 ;-493)\end{array}$

\begin{tabular}{|c|c|}
\hline CPX test & $\begin{array}{l}0.72(0.64- \\
0.81)\end{array}$ \\
\hline
\end{tabular}

Mammography $\quad 0.98(0.93-2424 \quad-1.4(-4.8 ; 2) \quad-34(-116 ; 48)$

‡: Non-statistically significant in the multivariate binomial models.

All models had a p-value lower than 0.001 , except those marked as $\ddagger$

All models were adjusted for first level covariates (consultation), i.e., patient's age, patient's Charlson Comorbidity Index, prenatal care consultation, time, and medical category; and for second level covariates - SDI and patient's sex. Gynecology, Gynecologic Surgery and Mammography considered only women as population at risk. 
Table 3: Relative risk of a patient having a follow-up visit in PHC within three and six months after being referred to secondary care by Generalists (reference) or Family physicians. Rio de Janeiro, Brazil, 2015 - 2018.

\begin{tabular}{|c|c|c|}
\hline Medical Specialty & 3 months & 6 months \\
\hline \multicolumn{3}{|l|}{ Ambulatory care } \\
\hline Cardiology & $1.86(1.62 ; 2.14)$ & $1.74(1.48 ; 2.04)$ \\
\hline Neurology & $1.78(1.56 ; 2.03)$ & $1.74(1.49 ; 2.02)$ \\
\hline Psychiatry & $2.15(1.75 ; 2.64)$ & $2.05(1.62 ; 2.61)$ \\
\hline Dermatology & $1.42(1.30 ; 1.55)$ & $1.45(1.32 ; 1.60)$ \\
\hline Pulmonology & $1.73(1.41 ; 2.11)$ & $1.76(1.39 ; 2.23)$ \\
\hline Infectious Diseases & $2.02(1.47 ; 2.77)$ & $1.55(1.11 ; 2.17)$ \\
\hline Urology & $1.74(1.54 ; 1.98)$ & $1.79(1.55 ; 2.06)$ \\
\hline Allergology & $1.89(1.47 ; 2.41)$ & $1.97(1.50 ; 2.58)$ \\
\hline Nephrology & $2.17(1.74 ; 2.71)$ & $1.89(1.45 ; 2.46)$ \\
\hline Endocrinology & $1.74(1.44 ; 2.11)$ & $1.47(1.19 ; 1.82)$ \\
\hline Gastroenterology & $1.77(1.42 ; 2.20)$ & $1.92(1.48 ; 2.50)$ \\
\hline Angiology & $1.40(1.15 ; 1.70)$ & $1.40(1.12 ; 1.75)$ \\
\hline Rheumatology & $1.86(1.52 ; 2.28)$ & $1.58(1.25 ; 1.98)$ \\
\hline Physiotherapy & $1.73(1.58 ; 1.90)$ & $1.72(1.54 ; 1.92)$ \\
\hline Rehabilitation & $1.73(1.52 ; 1.97)$ & $1.55(1.34 ; 1.80)$ \\
\hline Ophthalmology & $1.62(1.54 ; 1.70)$ & $1.57(1.49 ; 1.66)$ \\
\hline ENT & $1.70(1.53 ; 1.89)$ & $1.52(1.36 ; 1.71)$ \\
\hline Orthopedics & 1.83 (1.69; 1.97) & $1.63(1.50 ; 1.78)$ \\
\hline Gynecology & $1.88(1.57 ; 2.25)$ & $1.78(1.45 ; 2.18)$ \\
\hline HRPC $\ddagger$ & $1.16(0.93 ; 1.44)$ & $0.92(0.71 ; 1.19)$ \\
\hline
\end{tabular}

Surgical evaluation

\begin{tabular}{lcr} 
Eye Surgery & $1.62(1.51 ; 1.74)$ & $1.45(1.34 ; 1.58)$ \\
\hline Gynecologic Surgery & $1.65(1.42 ; 1.93)$ & $1.55(1.30 ; 1.84)$ \\
\hline Orthopedic Surgery & $1.48(1.01 ; 2.16)$ & $1.22(0.81 ; 1.82)$ \\
\hline General Surgery & $1.74(1.56 ; 1.93)$ & $1.64(1.45 ; 1.84)$ \\
\hline Plastic Surgery & $1.51(1.30 ; 1.77)$ & $1.43(1.21 ; 1.68)$ \\
Vascular Surgery & $1.24(0.96 ; 1.60)$ & $1.51(1.14 ; 2.01)$ \\
\hline \multicolumn{1}{c}{ Diagnostic tests } & & $1.53(1.28 ; 1.84)$ \\
\hline Echocardiogram & $1.91(1.64 ; 2.23)$ &
\end{tabular}




\begin{tabular}{|lrr|}
\hline Spirometry & $1.48(1.15 ; 1.90)$ & $1.65(1.22 ; 2.23)$ \\
\hline EGD & $1.72(1.38 ; 2.15)$ & $1.43(1.12 ; 1.85)$ \\
\hline CPX test & $2.04(1.71 ; 2.43)$ & $2.17(1.75 ; 2.68)$ \\
\hline Mammography & $2.02(1.58 ; 2.58)$ & $1.70(1.27 ; 2.28)$ \\
\hline $\begin{array}{l}\text { †: Non-statistically significant in the multivariate binomial models. } \\
\text { All models had a p-value lower than } 0.001, \text { except those marked as } \neq\end{array}$ & $1.93(1.72 ; 2.17)$ \\
$\begin{array}{l}\text { All models were adjusted for first level covariates (consultation), i.e., patient's age, patient's Charlson Comorbidity } \\
\text { Index, prenatal care consultation, time, and medical category; and for second level covariates - SDI and patient's } \\
\text { sex. Gynecology, Gynecologic Surgery and Mammography considered only women as population at risk. }\end{array}$ \\
\hline
\end{tabular}

